\title{
DOI:
}

\section{LINGUISTIC AND REGIONAL STUDIES TEACHING PROBLEMS (for the purpose of integrated teaching of the Georgian language and culture)}

\author{
Tamar Gitolendia \\ Doctor of Philology, Professor \\ Sokhumi State University \\ (Tbilisi, Georgia) \\ e-mail: tamargitolendia@gmail.com \\ Madlena Ochigava \\ Doctor of Philology \\ Sokhumi State University \\ (Tbilisi, Georgia) \\ e-mail: madlenaochigava@gmail.com
}

\begin{abstract}
There are some teaching methodological problems on how to teach the Georgian as a second language. This article is devoted to the teaching problems of "Linguistic and regional studies" subject for the Georgian language learners. The curriculum includes integrated language and culture teaching, so that language learners, understanding the elements of Georgian socio-cultural consciousness, can orientate themselves in the Georgian-speaking world. The course will help the language learner to get acquainted with the Georgian culture and at the same time master the language skills. The paper provides ways to tackle the language teaching-related problems. Here is the optimal vision of teaching the subject of linguistics and area studies in the Georgian language. In this respect the paper has practical significance.
\end{abstract}

Keywords: linguistic and regional studies, Georgian language, Georgian language teaching

\section{ВОПРОСЫ ПРЕПОДАВАНИЯ ПРЕДМЕТА ЛИНГВОСТРАНОВЕДЕНИЯ (с целью комплексного обучения грузинскому языку и культуре)}

\author{
Тамар Гитолендиа \\ Доктор филологии, профессор \\ Сухумский государственный университет \\ (Тбилиси, Грузия) \\ e-mail: tamargitolendia@gmail.com \\ Мадлена Очигава \\ Доктор филологии \\ Сухумский государственный университет \\ (Тбилиси, Грузия) \\ e-mail: madlenaochigava@gmail.com
}

\begin{abstract}
Аннотация. В преподавании грузинского как второго языкасуществуют определенные методические проблемы. Данная статья посвящена вопросам преподавания предмета лингвострановедения для изучающих грузинский язык. Учебный курс включает интегрированное обучение языку и культуре, так как понимая элементы грузинского культурного сознания, изучающие язык смогут лучше ориентироваться в грузиноязычном мире. Учебный курс поможет учащимся параллельно знакомиться с грузинской культурой и овладеть языком. В статье представлены способы решения
\end{abstract}


проблемы, связанной с преподаванием. Здесь приведено оптимальное видение преподавания предмета лингвострановедения на грузинском языке. В связи с этим статья имеет практическое значение.

Ключевые слова: лингвострановедение, грузинский язык, преподавание грузинского языка

\section{ВВЕДЕНИЕ}

Данная статья посвящена вопросам преподавания предмета лингвострановедения для изучающих грузинский язык. Учебный курс включает интегрированное обучение языку и культуре, чтобы изучающие язык, понимая элементы грузинского культурного сознания, могли лучше ориентироваться в грузиноязычном мире.

В Грузии, со времен Советского Союза, вопрос преподавания грузинского как второго языка не был актуален, поэтому широкий выбор учебников для изучающих грузинский язык практически отсутствовал. После распада Советского Союза, когда Грузия получила независимость, поэтапно стали решать ряд вопросов, и с 2004 года стали возможны основательные реформы системы образования. С 2010 года в контексте реформы образования встал вопрос преподавания государственного языка для этнических меньшинств, проживающих в Грузии. С этой целью было разработано видение, согласно которому в грузинских высших учебных заведениях были запущены программы преподавания грузинского языка, что позволило бы представителям малочисленных этнических групп, проживающих в Грузии, легко изучать и сдавать государственный язык при поступлении в вузы. Кроме того, в последние годы все больше и больше иностранных студентов приезжают в Грузию с целью получения образования. Наше государство также привлекает внимание своим географическим положением или политическими и торговыми интересами, благодаря чему многие иностранцы работают в Грузии. Эти обстоятельства делают вопрос изучения грузинского как второго языка более актуальным.

В рамках программы преподавания и обучения грузинскому как второму языку были созданы многочисленные печатные и электронные учебники на грузинском языке. Примечательно, что опыт показал, что первые книги-учебники, составленные после внедрения программы, были подготовлены в спешке по той причине, что не было как современной методической литературы для преподавания грузинского языка, так и опыта преподавания грузинского языка. Почти 10-летняяпрактика показала, что существующие учебники нуждаются в доработке. Учебники грузинского языка, изданные в последние годы, методически совершенствуются, но в этом направлении еще предстоит проделать большую работу.

\section{ОБЗОР ВОПРОСА (ОБЗОР НАУЧНОЙ ЛИТЕРАТУРЫ ПО ПРОБЛЕМЕ)}

Как известно, цель преподавания предмета страноведения- подготовить изучающего язык к общению на новом языке. В методической литературе по изучению языков различают два подхода к преподаванию лингвострановедения: 1) когда в обучении используется так называемые языковые тексты, отражающие «высокую культуру», и 2) т. н. тексты, отражающие «бытовую культуру». В специальной литературе при обсуждении обоих подходов отмечаются их сильные и слабые стороны. В частности, обучение с элементами «высокой культуры» считается устаревшим традиционным методом, в то время как обучение с элементами «бытовой культуры», которая также считается неотъемлемой частью культуры страны, предлагает изучающим язык «банальную» информацию, которая скоро теряет актуальность, а учебные материалы быстро «устаревают».

\section{МЕТОДЫ ИССЛЕДОВАНИЯ}

При работе над вопросом используется метод критического прочтения методической литературы, метод непосредственного наблюдения за процессом обучения, метод анализа опыта и подведения итогов. 


\section{РЕЗУЛЬТАТЫ И ОБСУЖДЕНИЕ}

Существует несколько причин, по которым мы считаем целесообразным ведение курса лингвострановедения (факультативного или обязательного) с текстами, отражающими «высокую культуру»: а) учебные материалы, необходимые для знакомства с «бытовой культурой», разбросаны по существующим учебникам, с помощью которых учащийся может выучить современный коммуникативный словарь и тексты; и б) Грузия - страна с великой историей, и это то, что привлекает многих иностранцев.

Помимо не говорящих по-грузински граждан Грузии (азербайджанцев, армян и др.), существует новое поколение грузинских эмигрантов, проживающих в разных странах мира, оторванных от своего родного языка и культуры, которые заинтересованы в изучении грузинского языка. Они, как и их родители, наверняка хотели бы, чтобы поколение, выросшее в эмиграции, знало свой родной язык и грузинскую культуру. В связи с историческими событиями три грузинских диалекта (ингилойский, имерхевский, ферейданский) были отрезаны от Грузии, но несмотря на это, так называние «чвенебуреби» (свои) стараются сохранить язык и активно восстанавливают контакты с Грузией.

В последние годы в школах Гальского района сокращалось количество уроков грузинского языка и литературы, теперь же грузинский язык исключен из учебной программы, а новое поколение, проживающее там, лишено права учиться на своем родном языке. Если такая ситуация будет продолжаться долгое время, то у грузинского населения Гали возникнет серьезная проблема со знанием грузинского языка и культуры. Примечателен тот факт, что выпускникам школ Гальского района, которые сейчас учатся в грузинских вузах, уже сложно уверенно говорить по-грузински из-за пониженной языковой компетенции, они воздерживаются от участия в семинарах, затрудняются излагать свое мнение.

Проблема заключается в том, что почти во всех вузах, где есть подготовительная программа обучения грузинскому языку, преподается лингвострановедение, но нет соответствующего учебника, поэтому преподавателям приходится искать тексты самостоятельно. Основываясь на наших практических наблюдениях, учебный материал содержит лексику высокого стиля, из-за чего изучающим грузинский язык сложно воспринимать и понимать сложные / устаревшие слова и синтаксические конструкции. При составлении учебника по лингвострановедению необходимо учитывать правила адаптации текста, что подразумевает сокращение использования в тексте связующих слов, упрощение предложений, конкретность (без использования художественного языка), выбор часто употребляемой лексики, соблюдение логической последовательности повествования. Материал должен быть составлен на понятном и простом языке. Не следует использовать длинные сложные предложения.

Преподавание данной дисциплины имеет особое значение для культурной, социальной и даже политической интеграции в грузинское общество негрузиноязычных малочисленных этнических групп, компактно проживающих на территории Грузии. Это будет способствовать тому, чтобы они осознали себя полноправными членами (детьми) своей исторической родины. Очень часто учителю приходится брать на себя большую ответственность выбирая подходящий материал, так как история Кавказа - это история войн, а Южный Кавказ включает в себя ряд замороженных или активных межнациональных конфликтов. Игнорирование этих тем не является наилучшим решением. Главное - правильно и объективно их преподнести, и беспристрастно разобрать их перед аудиторией. Мы думаем, что каждый правильный шаг в этом направлении поможет ослабить эти конфликты и избежать их в будущем.

Лингвострановедение - как междисциплинарный курс гуманитарных и социальных наук, мы считаем, должен предусматривать преподавание таких вопросов, как: территория расселения грузин (местоположение, климат, границы), демографическое положение грузин, древние грузинские племена, названия, обозначающие грузин, основание грузинской государственности. Грузинский 
язык и вопросы истории его развития, диалекты грузинского языка, грузинская письменность, древние рукописи, грузинские верования. Историко-этнографические аспекты Грузии, города Грузии, природа Грузии - горы, реки, озера и пещеры, морские и горные курорты, минеральные воды, грузинское сельское хозяйство, виноградарство и виноделие, вспомогательные отрасли сельского хозяйства, ремесла, формы поселений, жилые постройки, грузинский народный транспорт. Праздники в Грузии - «Новый год», «Гиоргоба», «День Независимости», и др., грузинские блюда, столовый этикет, традиции гостеприимства, грузинское застолье, традиция тамады, грузинская одежда. Антропонимическая модель, система собственных имен, свадебные обычаи, семейная жизнь, формы искусственного родства, обычаи-правила воспитания детей, традиции народной медицины, похоронные обряды. Памятники грузинского литературного языка, «Мученичество Шушаник» и грузинское богословское письмо. «Витязь в тигровой шкуре» и грузинская культура, фреска Руставели в Квабисхеви. Грузинское народное устное творчество. Грузинская архитектура и прикладное искусство, памятники: Гелати, Светицховели, Джвари, дворец Дадиани. Грузинские народные песни и танцы, классический грузинский балет, грузинское кино и театр. Выдающиеся грузинские актеры, грузинская живопись. Пиросмани, Л. Гудиашвили, Э. Ахвледиани и др.; грузинский народный спорт. Этносы в Грузии, межэтнические отношения. ${ }^{1}$

Названные темы должны сопровождаться соответствующими упражнениями, и, что самое главное, учебник должен содержать иллюстрации, так как визуализация - это отличный способ для изучающего язык получить представление об изучаемом материале.

Считаем целесообразным знание грузинского языка на уровне А2 в качестве предварительного условия для использования учебника. С точки зрения возраста он должен быть понятным и интересным для учащихся начиная с 11-летнего возраста.

\section{ЗАКЛЮЧЕНИЕ}

Таким образом, одним из необходимых условий преподавания лингвострановедения является соблюдение принципа интегрированного обучения предмету и языку. Этот метод активно используется в обучении государственному грузинскому языку студентов-представителей негрузиноязычного населения. Например, такие дисциплины, как «Грузинский отраслевой язык», «Разнообразие и толерантность» и др., студентам предоставляются в форме интегрированного обучения языку и предмету. Второй важный принцип - «от простого к сложному» или постепенное последовательное усложнение материала -каждый новый уровень должен основываться на том, что уже изучено, что создает дополнительные трудности для учителей.

Планирование учебника по лингвострановедению в рамках вышеупомянутого подхода, наряду с обучением грузинскому языку, также означает знакомство с культурой. Он поможет изучающему язык познакомиться с грузинской культурой через простые тексты и в то же время овладеть языком, будет содействовать сохранению и распространению грузинского языка и культуры, в том числе за пределами Грузии, в центрах изучения языков и в системе университетского образования. Введение учебного курса позволит заинтересованному субъекту использовать альтернативный способ преподавания / обучения.

\section{REFERENCES}

Topchishvili Roland, „Sakartvelos etnograpia / etnologia“, Izdatelstvo „Universal“, Tbilisi, 2010, 737 s. http://geofl.ge/lego/lessonViewWithoutAdds.php?text=\%E1\%83\%A1\%E1\%83\%AC\%E1\%83 \%90\%E1\%83\%95\%E1\%83\%9A\%E1\%83\%94\%E1\%83\%91\%E1\%83\%98\%E1\%83\%A1\%

\footnotetext{
${ }^{1}$ Указанные вопросы были проработаны и опубликованы в книге под общей редакцией этнолога Роланда Топчишвили. См. Topchishvili Roland, „Sakartvelos etnograpia / etnologia“, Izdatelstvo „Universal“, Tbilisi, 2010, s.737 88
} 
20\%E1\%83\%9B\%E1\%83\%94\%E1\%83\%97\%E1\%83\%9D\%E1\%83\%93\%E1\%83\%98\%E 1\%83\%99\%E1\%83\%90\%20\%E1\%83\%AC\%E1\%83\%98\%E1\%83\%92\%E1\%83\%9C\%E1 \%83\%98\%20\%E1\%83\%97\%E1\%83\%90\%E1\%83\%95\%E1\%83\%98\%2010\&parentID=59 (Дата обращения 29.09.2020)

Karpets, L. \& Kucherenko, H. (2019) Inter-ethnic communication in language teaching II International Scientific-Pedagogical Organization of Philologists “WEST-EAST " (ISPOP). Scientific Journal WEST-EAST. Vol 2/1 N1 (October, 2019). pp. 152-156. doi: https://doi.org/10.33739/2587-54342019-2-152-156

Tareva, E.G. (2019) CULTURE IN THE SPACE OF LINGUODIDACTIC CONCEPTOLOGY ॥ International ScientificPedagogical Organization of Philologists “ WEST-EAST ” (ISPOP). Scientific Journal WEST-EAST. Vol 2/1 N1 (October, 2019). pp. 123-127. doi: https://doi.org/10.33739/25875434-2019-2-123-127

\section{For citation:}

Gitolentia, T. \& Ochigava, M. (2020). Linguistic and regional studies teaching problems (for the purpose of integrated teaching of the Georgian language and culture) // International ScientificPedagogical Organization of Philologists “WEST-EAST" (ISPOP). Scientific Journal WEST-EAST. Vol 3 N1 (October, 2020). pp. 78-82. doi:

\section{Для цитирования:}

Гитолентия, Т., Очигава, М. (2020). Вопросы преподавания предмета лингвострановедения (с целью комплексного обучения грузинскому языку и культуре) // International Scientific-Pedagogical Organization of Philologists “WEST-EAST” (ISPOP). Scientific Journal WEST-EAST. Vol 3 N1 (October, 2020). C. 78-82. doi:

\section{Information about the authors:}

Tamar Gitolandia - Doctor of Philology, Professor of Humanitarian Faculty, Department of Georgian Philology, Sukhumi State University, Tbilisi, Georgia

e-mail: tamargitolendia@gmail.com

Madlena Ochigava - Doctor in Philology, Faculty of Humanities, Head of the Georgian Language 1+4 Preparatory Program, Sukhumi State University, Tbilisi, Georgia e-mail: madlenaochigava@gmail.com

\section{Сведения об авторах:}

Тамар Гитолендиа - доктор филологии, профессор гуманитарного факультета, направление «Грузинская филология», Сухумский государственный университет, Тбилиси, Грузия e-mail: tamargitolendia@gmail.com

Мадлена Очигава - доктор филологии, гуманитарного факультета, руководитель подготовительной программы по грузинскому языку $1+4$, Сухумский государственный университет, Тбилиси, Грузия e-mail: madlenaochigava@gmail.com

Manuscript received: $12 / 08 / 2020$

Accepted for publication: $12 / 09 / 2020$

Рукопись получена: $12 / 08 / 2020$

Принята к печати: 12/09/2020 